\title{
Experimental Measurements of the Volumetric Heat Transfer Coefficient between Forced Air and Sand at Reynold's Numbers Relevant to Smouldering Combustion
}

\author{
Marco A. B. Zanoni ${ }^{1}$, Jason I. Gerhard ${ }^{1}$, Jose L. Torero ${ }^{2}$ \\ ${ }^{1}$ Department of Civil and Environmental Engineering, University of Western Ontario \\ London, ON, Canada \\ mbazelat@uwo.ca; jgerhard@uwo.ca \\ ${ }^{2}$ School of Civil Engineering, University of Queensland \\ Brisbane, QDL 4072, Australia \\ j.torero@uq.edu.au
}

\section{Extended Abstract}

Smouldering combustion, a flameless form of combustion [1], is the governing process of an innovative soil remediation technology called Self-sustaining Treatment for Active Remediation (STAR) [2, 3]. STAR has been shown to be an effective approach for destroying oily contaminants in soil with minimal energy input. Smouldering has long been studied in a fire safety context, focused almost exclusively on porous solid fuels (e.g., foam, coal); very little is known about smouldering of liquid hydrocarbons in an inert porous matrix (e.g., coal tar in sand). Moreover, smouldering is a complex thermodynamic process, involving pyrolysis and oxidation reactions, local thermal non-equilibrium between solid and gas temperatures, multiple heat transfer mechanisms and ultimately a balance between energy recirculated ahead of the front and heat losses. Modelling of liquid smouldering presents several challenges, the main one being the unknown volumetric heat transfer coefficient between solid and gas phases $\left(h_{v}\right)$. While literature correlations for $h_{v}$ exist, they are not appropriate for the low Reynolds numbers of smouldering systems.

The main objective of this study was to model heat transfer in sand under forced air flow conditions relevant to smouldering systems. To achieve this, a new empirical correlation was developed for the volumetric heat transfer coefficient (hv) between forced air and sand at low Reynolds numbers. Nineteen experiments were conducted in a onedimensional column to evaluate the volumetric heat transfer coefficient for different air injection rates and sand particle diameters. A 1D numerical model based on local thermal non-equilibrium and Darcy flow was developed to evaluate the temperature of the solid (sand) and fluid (air) phases. The thermal properties of sand, measured with the Transient Plane Source (TPS) method (Hot Disk Thermal Constants Analyser) [4] at elevated temperatures, were used. The volumetric heat transfer coefficient was then obtained through an optimization technique (inverse modelling), minimizing the least-squares error between the experimental and numerical sand temperature for each experiment. In this way, a new empirical Nusselt vs Reynolds and Prandtl numbers correlation was developed. This provides a new correlation available for all similar low Reynolds number systems. As well, it provides a key step towards modelling the propagation of a self-sustaining smouldering reaction in liquid fuel (contaminated soil) systems.

\section{References}

[1] T. J. Ohlemiller, "Modeling of smoldering combustion propagation," Progress in Energy and Combustion Science, vol. 11, pp. 277-310, 1985.

[2] P. Pironi, C. Switzer, G. Rein, A. Fuentes, J. I. Gerhard, and J. L. Torero, "Small-scale forward smouldering experiments for remediation of coal tar in inert media," in Proceedings of the Combustion Institute, vol. 32, pp. 19571964, 2009.

[3] C. Switzer, P. Pironi, J. I. Gerhard, G. Rein, and J. L. Torero, "Self-Sustaining Smoldering Combustion: A Novel Remediation Process for Non-Aqueous-Phase Liquids in Porous Media," Environmental Science \& Technology, vol. 43, pp. 5871-5877, 2009. 
[4] S. E. Gustafsson, "Transient plane source techniques for thermal conductivity and thermal diffusivity measurements of solid materials," Review of Scientific Instruments, vol. 62, pp. 797-804, 1991. 